\title{
The Importance of Serotonin in Exercise-Induced Adult Neurogenesis: New Evidence from Tph $2^{-/-}$Mice
}

\author{
Danielle Beckman ${ }^{1 \star}$ and Luís Eduardo Santos ${ }^{2 *}$ \\ ${ }^{1}$ Institute of Medical Biochemistry, ${ }^{2}$ Carlos Chagas Filho Institute of Biophysics, Federal University of Rio de Janeiro, Rio de Janeiro, RJ 21941-902, Brazil \\ Review of Klempin et al.
}

The neurotransmitter serotonin (5-HT) is a well established modulator of adult neurogenesis. In the last decade, several lines of research involving pharmacological enhancement of 5-HT levels, depletion of serotonergic neurons and direct activation of 5-HT receptors have shown consistently that 5-HT may enhance the production of new neurons in prominent neurogenic niches in the brain, including the dentate gyrus (DG) of the hippocampus (Doze and Perez, 2012). This effect of 5-HT is also considered to have important functional significance. Most antidepressant drugs target the monoaminergic systems increasing hippocampal neurogenesis, and reduced levels of neurogenesis are common among patients suffering from major depression disorder (MDD) (Dranovsky and Hen, 2006).

Physical exercise is another important neurogenic stimulus, which has been shown to have positive effects on mood, learning and memory in humans, both young and old, as well as in rodents. There is currently great interest in these effects and their possible implications for the prevention and managing of Alzheimer's

\footnotetext{
Received July 9, 2013; revised Aug. 2, 2013; accepted Aug. 5, 2013. *D.B. and L.E.S. contributed equally to this work.

This work was supported by grants from Conselho Nacional de Desenvolvimento Científico e Tecnológico.

Correspondence should be addressed to Luís Eduardo Santos, Carlos Chagas Filho Institute of Biophysics, Federal University of Rio de Janeiro, Rio de Janeiro, RJ 21941-902, Brazil. E-mail: Isantos@biof.ufrj.br. DOI:10.1523/JNEUROSCI.2911-13.2013

Copyright $\odot 2013$ the authors $\quad 0270-6474 / 13 / 3314283-02 \$ 15.00 / 0$
}

disease and similar pathologies (van Praag, 2009; Hötting and Röder, 2013). The literature on exercise in mice is vast, and includes numerous different protocols, among which voluntary wheel running is one of the most commonly used. This task has been linked to increased neurogenesis in the DG, as well as improved performance in spatial learning and contextual memory consolidation paradigms (van Praag, 2009).

In addition to neurogenesis, other alterations may be observed in the CNS in response to physical exercise. Synaptogenesis and angiogenesis are induced, likely as a result of increased production and release of brain-derived neurotrophic factor (BDNF) and insulin-like growth factor-1 (IGF-1). Most notably however, neurotransmitter availability is also modulated by exercise. The basal levels of monoamines such as 5-HT and noradrenaline increase in the brain of rodents that practice wheel running (Lista and Sorrentino, 2010). In light of the many links described in recent literature, 5 -HT is regarded as one of the candidate molecules to directly relate physical exercise to neurogenesis. However, up until very recently, the question of whether the neurogenic effect of running is dependent on 5-HT production remained unaddressed. In a paper published in The Journal of Neuroscience, Klempin et al. (2013) sought to answer this question using mice lacking tryptophan hydroxylase type $2\left(T p h 2^{-l-}\right)$, the ratelimiting enzyme in 5-HT production in the CNS.
Tph $2^{-1-}$ mice were first developed in 2008, nearly simultaneously by three independent groups, and they display a complete loss of brain 5-HT (Gutknecht et al., 2008; Savelieva et al., 2008; Alenina et al., 2009). Despite the deficiency in the neurotransmitter, serotonergic fibers were shown to be morphologically unaltered in these animals (Gutknecht et al., 2008). It is also noteworthy that $T p h 2^{-1-}$ mice are born visually indistinguishable from control littermates, but show alterations in postnatal development, including slower growth, slower weight gain and behavioral changes, such as increased aggressiveness. Brain morphology is however normal, and Tph $2^{-1-}$ animals are fertile (Alenina et al., 2009).

Using the S-phase mitosis marker Bromodeoxyuridine (5-bromo-2'-deoxyuridine, BrdU) Klempin et al. initially showed that Tph $2^{-1-}$ mice had no significant changes in the total number of proliferating cells in the DG of the hippocampus, compared with wild-type animals. This finding is unexpected, because several authors have shown that partial lesions to the raphe nuclei, and consequent reduction of serotonergic neurons, result in decreased hippocampal neurogenesis (Doze and Perez, 2012). Klempin et al. (2013) conclude that compensatory changes taking place during the development of these knock-out animals are likely involved, balancing out the effects of the lack of 5-HT in normal neurogenesis. Nonetheless, when Tph $2^{-1-}$ mice and their wild-type littermates were allowed to engage in voluntary wheel running, an interesting difference emerged. As expected, 
after a $6 \mathrm{~d}$ period with unlimited access to a running wheel, wild-type mice showed a robust increase in neurogenesis compared with sedentary controls. Tph $2^{-1-}$ mice, in contrast, showed no significant exerciseinduced increase in neurogenesis. As argued by the authors, this observation suggests a crucial role of 5-HT in exerciseinduced neurogenesis, because no other mechanisms compensated for its absence during the running period.

In addition to the clear serotonergic deficit, Gutknecht et al. (2012) recently showed that Tph $2^{-1-}$ mice have considerable reductions in noradrenaline levels in several regions of the brain, such as the rostral raphe (28.3\% reduction), the hippocampus (38.6\% reduction), and the locus coeruleus (33.8\% reduction). This observation might be relevant to the lack of exercise-induced neurogenesis reported by Klempin et al. (2013). Parallels between the serotonergic and noradrenergic systems are well established in the literature, especially in pathologies such as MDD, where 5-HT/ noradrenaline reuptake inhibitors (SSRIs) are commonly used. Most importantly, DG neurogenesis may be positively modulated by noradrenaline to a similar extent as it is by 5 -HT. Noradrenergic terminals are abundant in the DG, and depleting them through lesion of the locus coeruleus results in a significant reduction in neurogenesis in rodents, comparable to what is seen after loss of serotonergic terminals (Dranovsky and Hen, 2006).

Dopamine levels are also significantly reduced in the hippocampus of Tph $2^{-1-}$ mice $(71.9 \%$ reduction) (Gutknecht et al., 2012). Relatively few studies have investigated the participation of dopamine in adult neurogenesis, and those that have produced some conflicting results. However, it has recently been noted that this neurotransmitter may be involved in controlling the proliferation of progenitor cells in the DG (Doze and Perez, 2012) and, consequently, fluctuations in hippocampal dopamine levels could have a role in the results reported by Klempin et al. (2013).

The proliferation and subsequent fate of progenitor cells in the DG of wild-type and $T p h 2^{-1-}$ mice with or without access to a running wheel was also addressed by Klempin et al. (2013). Using GFAP, DCX, and SOX2 labeling, the authors found that there were a similar number of quiescent,
$\mathrm{GFAP}^{+}$progenitors (known as type 1 cells), in the DG of all tested groups. However, proliferating, $\mathrm{SOX}_{2}{ }^{+}$and $\mathrm{DCX}^{+}$ progenitors (known as type $2 \mathrm{a}$ and type $2 \mathrm{~b} / 3$ cells, respectively) were significantly increased in wild-type mice after running, but not in Tph $2^{-1-}$ littermates. An increase in basal levels of type 2 a cells was also noted in Tph $2^{-1-}$ animals compared with wild-type controls. Further labeling the cells for caspase-3, a marker of apoptosis, revealed that the number of caspase $3^{+} /$ $\mathrm{SOX}^{+}{ }^{+}$cells was increased in knock-out animals. Together, these data led to the conclusion that enduring changes in the rates of proliferation and apoptosis of DG progenitors take place in the absence of 5-HT. Increased proliferation of SOX $2{ }^{+}$progenitors seemed to maintain basal neurogenesis of knockouts at normal levels, and this was accompanied by an increase in the number of apoptotic cells. When submitted to the effects of physical exercise, however, the progenitor cell pool apparently could not further increase without 5-HT, and neurogenesis levels in Tph $2^{-1-}$ animals failed to rise.

Last, Klempin and coworkers reported a large increase in the number of activated microglia in both wild-type and knockout animals after exercise. This effect was found to be significantly larger in Tph $2^{-1-}$ mice. Because such increased microgliosis is a known consequence of physical activity, the authors ascribe this difference between genotypes entirely to the increased apoptosis of progenitor cells seen in knockouts. It is important to note, however, that 5-HT may have an important anti-inflammatory effect on microglia. Recent work using SSRIs have shown that these drugs are capable of suppressing microglial responses to certain inflammatory stimuli, possibly through a protein kinase A (PKA)-dependent mechanism (Tynan et al., 2012). The larger increase in microglia seen in Tph $2^{-1-}$ mice could thus be to some extent related to a lack of 5-HTmediated microglial suppression. In addition, changes to microglial proliferation and activation state may also be closely linked to the activity of DG progenitors in response to exercise, as recently reported by Vukovic and coworkers (2012). Klempin et al. (2013) makes interesting and promising points to be addressed in the future, and the Tph $2^{-1-}$ mouse model continues to be a valuable tool for the study of brain 5-HT. As a mediator of exercise-induced adult neurogenesis, 5-HT may be an old target for new approaches to prevalent CNS pathologies, such as MDD.

\section{References}

Alenina N, Kikic D, Todiras M, Mosienko V, Qadri F, Plehm R, Boyé P, Vilianovitch L, Sohr R, Tenner K, Hörtnagl H, Bader M (2009) Growth retardation and altered autonomic control in mice lacking brain serotonin. Proc Natl Acad Sci USA 106:10332-10337. CrossRef Medline

Doze VA, Perez DM (2012) G-protein-coupled receptors in adult neurogenesis. Pharmacol Rev 64:645-675. CrossRef Medline

Dranovsky A, Hen R (2006) Hippocampal neurogenesis: regulation by stress and antidepressants. Biol Psychiatry 59:1136-1143. CrossRef Medline

Gutknecht L, Waider J, Kraft S, Kriegebaum C, Holtmann B, Reif A, Schmitt A, Lesch KP (2008) Deficiency of brain 5-HT synthesis but serotonergic neuron formation in Tph2 knockout mice. J Neural Transm 115:1127-1132. CrossRef Medline

Gutknecht L, Araragi N, Merker S, Waider J, Sommerlandt FMJ, Mlinar B, Baccini G, Mayer U, Proft F, Hamon M, Schmitt AG, Corradetti R, Lanfumey L, Lesch KP (2012) Impacts of brain serotonin deficiency following Tph2 inactivation on development and raphe neuron serotonergic specification. PLoS One 7:e43157. CrossRef Medline

Hötting K, Röder B (2013) Beneficial effects of physical exercise on neuroplasticity and cognition. Neurosci Biobehav Rev pii:S0149-7634 (13)00101-2. CrossRef Medline

Klempin F, Beis D, Mosienko V, Kempermann G, Bader M, Alenina N (2013) Serotonin is required for exercise-induced adult hippocampal neurogenesis. J Neurosci 33:8270-8275. CrossRef Medline

Lista I, Sorrentino G (2010) Biological mechanisms of physical activity in preventing cognitive decline. Cell Mol Neurobiol 30:493-503. CrossRef Medline

Savelieva KV, Zhao S, Pogorelov VM, Rajan I, Yang Q, Cullinan E, Lanthorn TH (2008) Genetic disruption of both tryptophan hydroxylase genes dramatically reduces serotonin and affects behavior in models sensitive to antidepressants. PLoS One 3:e3301. CrossRef Medline

Tynan RJ, Weidenhofer J, Hinwood M, Cairns MJ, Day Ta and Walker FR (2012) A comparative examination of the anti-inflammatory effects of SSRI and SNRI antidepressants on LPS stimulated microglia. Brain Behav Immun 26: 469-479. CrossRef Medline

van Praag H (2009) Exercise and the brain: something to chew on. Trends Neurosci 32: 283-290. CrossRef Medline

Vukovic J, Colditz MJ, Blackmore DG, Ruitenberg MJ, Bartlett PF (2012) Microglia modulate hippocampal neural precursor activity in response to exercise and aging. J Neurosci 32:6435-6443. CrossRef Medline 